\title{
Mineral Retention in Three-Week-Old Piglets Fed Goat and Cow Milk Infant Formulas
}

\author{
S. M. Rutherfurd, ${ }^{\star 1}$ A. J. Darragh, ${ }^{\star}$ W. H. Hendriks, ${ }^{\star}$ C. G. Prosser, $†$ and D. Lowrył \\ *Institute of Food, Nutrition and Human Health, Massey University, Palmerston North, New Zealand \\ †AgResearch, Private Bag 3123, Hamilton, New Zealand \\ ‡Dairy Goat Co-operative (N.Z.) Ltd., Hamilton, New Zealand
}

\section{ABSTRACT}

Goat milk and cow milk are commonly used in infant formula preparations and, as such, understanding the nutritional characteristics of infant formulas made from these milks is important. In this study, a goat milk infant formula was compared with an adapted (whey-enhanced) cow milk infant formula with respect to mineral absorption and deposition using the 3-wkold piglet as a model for the 3-mo-old infant. Equal numbers of piglets $(n=8)$ were fed either the goat milk formula or the cow milk formula. The mineral composition of the prepared goat milk formula was higher than that of the prepared cow milk formula for most minerals, including calcium ( 75.1 vs. $56.7 \mathrm{mg} /$ $100 \mathrm{~mL}$ ) but excluding iron, which was higher in the prepared cow milk formula ( $0.92 \mathrm{vs} .0 .74 \mathrm{mg} / 100 \mathrm{~mL}$ ). The amounts of calcium, phosphorus, and manganese absorbed by the piglets were significantly higher for the goat milk formula, whereas the amounts of zinc, iron, and magnesium absorbed were significantly higher for the cow milk formula. Apparent mineral absorption, relative to intake, was statistically higher in the cow milk formula for calcium and phosphorus, although the actual differences were very small (less than $1.3 \%)$. For copper, zinc, iron, and magnesium there was no significant difference between treatments in apparent mineral absorption, whereas for manganese, absorption was higher for the goat milk infant formula. The absolute mineral deposition was higher in piglets fed the goat milk formula for calcium, phosphorus, and manganese, whereas iron deposition was higher in the piglets fed cow milk formula. For all other minerals tested, there were no significant differences between treatments. The goat milk infant formula provided a pattern of mineral retention in the 3 -wk-old piglet very similar to that of the adapted cow milk infant formula. The minor differences observed between the 2 appeared

Received May 8, 2006.

Accepted June 21, 2006.

${ }^{1}$ Corresponding author: S.M.Rutherfurd@massey.ac.nz to be due to the different mineral contents of the 2 formulas.

Key words: goat milk, infant formula, mineral

\section{INTRODUCTION}

Cow milk is the most commonly used animal protein source for the preparation of infant formula. However, goat milk infant formulas are also used as an alternative to cow milk. A considerable volume of work has been published on the nutritional value of cow milk and cow milk infant formulas. However, much less information is available in the literature on goat milk and goat milk infant formulas. The composition of goat milk has been characterized in relation to the particular proteins, fats, and minerals present and how these compare with cow milk (Jenness, 1980; Haenlein, 2004). More detailed analyses of the AA content (D'Urso, 2000; Roncada et al., 2002), total fat content, fatty acid composition, and mineral content (Sawaya et al., 1984; Rodrigeuz Rodrigeuz et al., 2002) of goat milk have also been reported.

Few studies have investigated the bioavailability of nutrients from goat milk. Nitrogen and mineral digestibility has been determined for unfortified goat milk and compared with cow milk (Murry et al., 1999). Other studies have investigated the uptake of specific minerals from goat milk in healthy (Lopez-Aliaga et al., 2000) and anemic (Park et al., 1986) rats or rats with intestinal resection (Barrionuevo et al., 2002; Alferez et al., 2003; Campos et al., 2003). A recent clinical trial showed that goat milk infant formula can support growth in healthy newborn infants equivalent to an adapted cow milk infant formula (Grant et al., 2005). Combined, these studies suggest that goat milk is a suitable source of nutrients for the production of infant formula, but no data exist on the nutritional adequacy or bioavailability of nutrients in goat milk infant formula.

We recently compared the AA content and true ileal AA digestibility of goat milk formula with cow milk formula in the 3-wk-old piglet (Rutherfurd et al., 2006). These findings were extended in the present study to 
examination of the mineral (calcium, phosphorus, zinc, iron, magnesium, copper, and manganese) bioavailability in goat milk infant formula, compared with a wheyenhanced cow milk infant formula. The 3 -wk-old piglet, which models the digestion of the 3-mo-old infant (Moughan et al., 1992; Darragh and Moughan, 1995), was used to provide detailed information on nutrient availability that cannot be determined by in vitro studies, suckling rat models, or trials with infants.

\section{MATERIALS AND METHODS}

The goat milk infant formula was obtained from the Dairy Goat Co-operative (N. Z.) Ltd., (Hamilton, New Zealand), and the cow milk infant formula was from Wyeth (Auckland, New Zealand). Both formulas are established commercial formulas representative of the predominant types of goat and cow formulas currently available internationally. The goat formula has goat milk protein as the sole protein source, and the cow milk formula contains cow milk and whey proteins (frequently referred to as "whey-enhanced" or "adapted").

\section{Piglet Trial}

All procedures involving animals were approved by the Massey University Animal Ethics Committee. Sixteen entire male piglets were obtained from a local producer at 1 wk of age and had received an iron injection as part of the normal piglet management at the property. Two infant formula diets were prepared according to the manufacturer's instructions (goat milk formula: $13.5 \mathrm{~g}$ plus $90 \mathrm{~mL}$ of water; cow milk formula: $12.7 \mathrm{~g}$ plus $90 \mathrm{~mL}$ of water). The piglets were housed in purpose-built plastic metabolism crates (Darragh and Moughan, 1995) at the Animal Physiology Unit, Massey University (Palmerston North). The crates were housed in a temperature-controlled room maintained at $28 \pm$ $2^{\circ} \mathrm{C}$ with a $16: 8 \mathrm{~h}$ light:dark cycle. The metabolism crates were equipped with urine collection assemblies to allow complete urine collection. The piglets underwent a 14-d acclimatization period, during which time they received a 1:1 mixture of the 2 infant formulas. At the beginning of the acclimatization period, each piglet was weighed. During the acclimatization period, the piglets received $345 \mathrm{~g}$ of liquid formula/kg of BW per d (Darragh and Moughan, 1995). The piglets were trained to drink from a bottle fitted with a rubber teat and were fed their daily ration as 7 equal meals ( $49 \mathrm{~g}$ of liquid formula/kg of BW) every $2.5 \mathrm{~h}$ from 0630 to $2130 \mathrm{~h}$. At the end of the acclimatization period, when the piglets were 3 wk of age, they were allocated to 1 of the 2 test diets, with each treatment balanced for littermates. A stomahesive base plate (designed to at- tach to human ostomy bags) was fitted over the anus of each pig. The plate was glued in place after the anal and tail region of the piglets had been shaved. A preweighed ostomy bag was then attached to the base plate to allow quantitative fecal collection. Each piglet was reweighed weekly and the respective food intake was adjusted for the increase in BW. The main trial lasted $11 \mathrm{~d}$, during which time the daily allowance was given as described for the acclimatization period. Each day, any formula that was refused or spilled was collected, dried, and weighed.

Urine was collected into a bottle containing $25 \mathrm{~mL}$ of $1.8 \mathrm{M} \mathrm{H}_{2} \mathrm{SO}_{4} / \mathrm{L}$ of urine and this, along with the feces, was collected separately each day. Urine and feces were then pooled, respectively, for each day over the collection period for each piglet. Each pooled urine sample for each pig was analyzed for creatinine and mineral contents. The diet and feces samples were freeze-dried and subsequently analyzed for mineral content. The total urinary and fecal mineral output, absorption, and retention of selected minerals for the piglets fed the 2 formulas were then calculated and compared.

Dietary mineral intake was calculated for each mineral and for total minerals as follows:

dietary mineral intake $(\mathrm{mg} / \mathrm{d}$ per $\mathrm{kg}$ of metabolic $\mathrm{BW})=$

$\underline{\text { mineral content of formula }(\mathrm{mg} / \mathrm{g} \text { of } \mathrm{DM}) \times \text { amount of formula consumed }(\mathrm{g} \text { of } \mathrm{DM} / \mathrm{d})}$ initial piglet $\mathrm{BW}^{(0.75)}$

Fecal mineral output was calculated for each mineral and for total minerals as follows:

fecal mineral output $(\mathrm{mg} / \mathrm{d}$ per $\mathrm{kg}$ of metabolic $\mathrm{BW})=$

fecal mineral content $(\mathrm{mg} / \mathrm{g}$ of $\mathrm{DM}) \times$ total fecal weight $(\mathrm{g})$ number of days in the trial period $\times$ initial piglet $\mathrm{BW}^{(0.75)}$

Apparent mineral absorption (\%) was calculated as follows:

apparent mineral absorption $(\%)=$

$\underline{\text { dietary mineral intake }(\mathrm{mg} / \mathrm{d}) \text { - fecal mineral output }(\mathrm{mg} / \mathrm{d})}$ dietary mineral intake $(\mathrm{mg} / \mathrm{d})$

Urinary mineral output was calculated for each mineral and for the total minerals as follows:

urinary mineral output $(\mathrm{mg} / \mathrm{d}$ per $\mathrm{kg}$ of metabolic $\mathrm{BW})=$ urinary mineral content $(\mathrm{mg} / \mathrm{L}) \times$ total urine volume $(\mathrm{L})$ number of days in the trial period $\times$ initial piglet $\mathrm{BW}^{(0.75)}$

Absolute mineral retention was calculated as follows: 
Table 1. Mineral content of the goat and cow milk infant formulas

\begin{tabular}{|c|c|c|c|c|}
\hline Item & Goat & Cow & Goat & Cow \\
\hline & \multicolumn{2}{|c|}{$\begin{array}{c}(\text { Per } 100 \mathrm{~g} \text { of } \\
- \text { dry powder })-\end{array}$} & \multicolumn{2}{|c|}{$\begin{array}{c}(\text { Per } 100 \mathrm{~mL} \text { of } \\
\left.- \text { prepared formula }^{1}\right)-\end{array}$} \\
\hline \multicolumn{5}{|c|}{ Macrominerals, mg } \\
\hline Calcium & 576 & 459 & 75.1 & 56.7 \\
\hline Phosphorus & 342 & 317 & 44.6 & 39.2 \\
\hline Magnesium & 48.9 & 50.5 & 6.4 & 6.2 \\
\hline \multicolumn{5}{|c|}{ Microminerals, $\mu \mathrm{g}$} \\
\hline Zinc & 4.3 & 4.5 & 0.56 & 0.56 \\
\hline Iron & 5.7 & 7.4 & 0.74 & 0.92 \\
\hline Copper & 440 & 450 & 57.4 & 55.6 \\
\hline Manganese & 130 & 120 & 17.0 & 14.8 \\
\hline
\end{tabular}

${ }^{1}$ Calculated mineral content in the formula after it had been prepared as accordingly to the manufacturer's instructions (cow milk infant formula: $12.7 \mathrm{~g}$ of formula with $90 \mathrm{~mL}$ of water; goat milk infant formula: $13.5 \mathrm{~g}$ of powder with $90 \mathrm{~mL}$ of water). A density of $1.03 \mathrm{~g} / \mathrm{mL}$ was assumed for the prepared formula.

absolute mineral retention $(\mathrm{mg} / \mathrm{d}$ per $\mathrm{kg}$ of metabolic $\mathrm{BW})=$

dietary mineral intake (mg/d per $\mathrm{kg}$ of metabolic BW)

- [daily fecal mineral output (mg/d per $\mathrm{kg}$ of metabolic BW)

+ daily urinary mineral output (mg/d per $\mathrm{kg}$ of metabolic BW)]

Utilization was calculated as follows:

$$
\text { utilization }(\%)=
$$

absolute mineral retention ( $\mathrm{mg} / \mathrm{d}$ per $\mathrm{kg}$ of metabolic BW) dietary mineral intake (mg/d per $\mathrm{kg}$ of metabolic BW)

The calcium content of the ulna bone was also determined as follows: On d 13 to 14 of the study, the piglets were fed their meals hourly starting at $0530 \mathrm{~h}$ and finishing at $0830 \mathrm{~h}$. On the last day, feeding of the piglets was staggered such that each piglet was fed 30 min apart. Seven hours after the start of the hourly feeding regimen, each piglet was anesthetized with halothane and then killed using an intercardial injection of sodium pentobarbitone. The ulna bone of the left front leg was then dissected out.

The calcium content of the ulna bone was determined by stripping as much muscle and connective tissue off the bone as possible. The stripped bone was then ashed at $500^{\circ} \mathrm{C}$ for $16 \mathrm{~h}$, and the calcium content of the bone ash was determined as described below. The results are presented as the percentage of calcium present in the ash. The results were related back to bone ash rather than original bone weight because it was not possible to completely clean the bones of the muscle and connective tissue that was present.

\section{Chemical Analysis}

Creatinine was determined in duplicate using the Jaffe method based on the method of Masson et al.
(1981). Minerals were analyzed singly using inductively coupled plasma mass spectrometry.

\section{Data Analysis}

Differences between dietary treatments were tested using least significant difference (GLM procedure; SAS Institute, 1999), with a significant difference recognized at $P<0.05$.

\section{RESULTS}

\section{Mineral Analysis of the Goat and Cow Milk Formulas}

The mineral contents of the cow and goat milk infant formulas used in this study are provided in Table 1. Of the minerals tested, the levels of zinc, magnesium, and copper were very similar (less than 5\% difference) in both the powdered and reconstituted formulas. The levels of calcium, phosphorus, and manganese were higher in the goat milk formula compared with the cow milk formula. The difference ranged from $8 \%$ for phosphorus and manganese to $25 \%$ for calcium on a powder basis, and these differences extended to $14 \%$ for phosphorus and manganese and to $32 \%$ for calcium when the formulas were mixed with water, according to the manufacturer's specifications. In contrast, the iron content was higher in the cow milk formula by $29 \%$ on a powder basis and by $23 \%$ in the formulas prepared ready to feed. The calcium:phosphorus ratio was higher in the goat milk formula (1.68) compared with its cow milk counterpart (1.45).

\section{Mineral Absorption}

Throughout the acclimatization period, the piglets appeared healthy and maintained a positive growth profile. Most piglets developed nutritional scours for up to $2 \mathrm{~d}$ during the acclimatization period, after which time they recovered and remained healthy for the balance of the trial. The mean initial BW of the piglets at the start of the experimental period was not significantly different between the 2 treatments, $3.4 \mathrm{~kg}$ for the piglets on the goat milk infant formula and $3.2 \mathrm{~kg}$ for the piglets on the cow milk infant formula.

The apparent mineral absorption is shown in Table 2. Calcium and phosphorus absorption was almost complete (in excess of 97\%) for both infant formulas. The percentage absorption of both minerals was significantly higher for the cow milk infant formula compared with the goat milk infant formula, although the actual differences were less than 1.3 percentage units. The apparent absorption of manganese was significantly higher for the goat milk formula compared with the 
Table 2. Apparent absorption (\%) of minerals present in either the goat milk formula or the cow milk formula

\begin{tabular}{lllll}
\hline & \multicolumn{2}{c}{ Mean } & & \\
\cline { 2 - 3 } Item & Goat & Cow & SE & Significance \\
\hline Macrominerals & & & & \\
$\quad$ Calcium & 97.2 & 98.5 & 0.30 & $*$ \\
$\quad \begin{array}{l}\text { Phosphorus } \\
\text { Magnesium }\end{array}$ & 97.3 & 98.1 & 0.27 & $*$ \\
Microminerals & 84.6 & 89.7 & 1.80 & NS \\
$\quad$ Zinc & 67.5 & 71.9 & 2.40 & NS \\
Iron & 55.9 & 63.0 & 4.05 & NS \\
Copper & 71.4 & 70.7 & 4.11 & NS \\
$\quad$ Manganese & 65.9 & 52.9 & 3.10 & $*$ \\
Total & 96.2 & 97.3 & 0.18 & NS \\
\hline
\end{tabular}

${ }^{1}$ Total mineral absorption was calculated based only on the minerals reported in this study. The total amounts of each mineral in the diets were added together to give the total mineral content for each diet, as was the total mineral content in the feces. Apparent absorption was calculated as for the individual minerals.

$* P<0.05$.

cow milk formula. This difference in absorption was on the order of 13 percentage units. There were no significant differences in the absorption of copper, zinc, magnesium, and iron between the 2 infant formulas. The absorption of iron, magnesium, copper, and zinc was considerably less than $100 \%$, with the absorption of magnesium being the highest at 85 and $90 \%$, and iron the lowest at 56 and $63 \%$ for the goat milk and cow milk infant formulas, respectively.

The apparent absorbed mineral content of the 2 formulas is shown in Table 3. The amounts of calcium, phosphorus, and manganese absorbed by the piglets were significantly higher for the goat milk formula, whereas the amounts of zinc, iron, and magnesium absorbed were significantly higher for the cow milk formula.

\section{Urinary Mineral Excretion}

The urinary excretion of minerals by piglets fed the 2 infant formulas is presented in Table 4 . Creatinine was used as a urinary marker. The mean creatinine excretion was not significantly different between the piglets fed the cow milk formula $(577 \pm 50 \mu \mathrm{mol} / \mathrm{d}$, mean $\pm \mathrm{SE}$ ) and those fed the goat milk infant formula (595 $\pm 98 \mu \mathrm{mol} / \mathrm{d}$ ). The urinary excretion of phosphorus, copper, manganese, zinc, iron, and magnesium per unit of creatinine was not significantly different between the 2 formulas. In contrast, the urinary excretion of calcium per unit creatinine was significantly higher in the piglets fed the goat milk formula compared with those fed the cow milk formula. The urinary excretion of calcium was $90 \%$ higher for the goat milk formula compared with the cow milk formula.

\section{Mineral Balance Study}

The absolute amount of minerals ingested by the piglets fed either a goat milk or a cow milk infant formula and the amount of each mineral excreted in either the feces or urine or retained in the piglet's body was calculated. The results are presented in Table 5. The proportion of ingested minerals either retained by the piglets or excreted in either the feces or urine is shown for piglets fed either the goat milk infant formula (Figure 1) or the cow milk infant formula (Figure 2). On a metabolic BW basis, there was no significant difference in the amounts of copper, zinc, or magnesium retained. In contrast, the retention of calcium, phosphorus, and manganese was significantly higher in the piglets fed the goat milk formula compared with those fed the cow milk formula, whereas iron retention was significantly higher in the piglets fed the cow milk formula. For calcium, the retention was $29 \%$ higher, on a metabolic BW basis, for the goat milk formula compared with the cow milk formula, and for phosphorus and manganese it was 14 and 55\% higher, respectively, in the goat milk formula compared with the cow milk formula. Iron retention was $37 \%$ higher in piglets fed the cow milk formula. The proportion of dietary minerals retained was significantly higher for the goat milk formula for

Table 3. Apparent absorbed mineral content of the goat milk and cow milk infant formulas

\begin{tabular}{|c|c|c|c|c|}
\hline \multirow[b]{2}{*}{ Item } & \multicolumn{2}{|c|}{ Absorbable mineral content } & \multirow{2}{*}{$\begin{array}{l}\text { Overall } \\
\mathrm{SE}\end{array}$} & \multirow[b]{2}{*}{ Significance } \\
\hline & Goat & Cow & & \\
\hline \multicolumn{5}{|c|}{ Macrominerals, mg/100 g of DM } \\
\hline Calcium & 560 & 452 & 1.6 & $* * *$ \\
\hline Phosphorus & 333 & 311 & 0.9 & $* * *$ \\
\hline Magnesium & 41 & 45 & 0.9 & $* *$ \\
\hline \multicolumn{5}{|c|}{ Microminerals, $\mu \mathrm{g} / 100 \mathrm{~g}$ of $\mathrm{DM}$} \\
\hline Zinc & 2.9 & 3.3 & 0.1 & $*$ \\
\hline Iron & 3.2 & 4.7 & 0.3 & $* *$ \\
\hline Copper & 314 & 318 & 18.4 & NS \\
\hline Manganese & 86 & 64 & 3.8 & $* *$ \\
\hline
\end{tabular}

$* P<0.05 ; * * P<0.01 ; * * * P<0.001$. 
Table 4. Urinary mineral excretion for the goat milk and cow milk infant formulas

\begin{tabular}{|c|c|c|c|c|}
\hline \multirow[b]{2}{*}{ Urinary excretion } & \multicolumn{2}{|c|}{ Mean } & \multirow{2}{*}{$\begin{array}{l}\text { Overall } \\
\text { SE }\end{array}$} & \multirow[b]{2}{*}{ Significance } \\
\hline & Goat & Cow & & \\
\hline \multicolumn{5}{|c|}{ Macrominerals, $\mathrm{mg} / \mu \mathrm{mol}$ of creatinine $^{1}$} \\
\hline Calcium & 147 & 78.2 & 13.2 & $* *$ \\
\hline Phosphorus & 10.9 & 9.8 & 2.0 & NS \\
\hline Magnesium & 42.7 & 48.5 & 5.4 & NS \\
\hline \multicolumn{5}{|c|}{ Microminerals, $\mu \mathrm{g} / \mu \mathrm{mol}$ of creatinine ${ }^{1}$} \\
\hline Zinc & 0.41 & 0.48 & 0.1 & NS \\
\hline Iron & 0.60 & 0.79 & 0.2 & NS \\
\hline Copper & 0.28 & 0.22 & 0.04 & NS \\
\hline Manganese & 0.04 & 0.04 & 0.01 & NS \\
\hline
\end{tabular}

manganese, whereas for calcium the relative retention was significantly higher for piglets fed the cow milk formula. For the remaining minerals tested, there were no significant differences in relative retention between the 2 formulas. For calcium and manganese, the absolute differences were small (less than 4 percentage units).

\section{Bone Calcium}

The mean $( \pm \mathrm{SE} ; \mathrm{n}=8)$ calcium content of the ulna bone in the piglets fed the goat milk infant formula was $76.9 \pm 0.6 \mathrm{~g} / 100 \mathrm{~g}$ of bone ash. This was not significantly different from that observed in the ulna bone of piglets fed the cow milk infant formula $(76.7 \pm 0.7 \mathrm{~g} / 100 \mathrm{~g}$ of bone ash).

\section{DISCUSSION}

The mineral contents of the goat and cow infant formulas varied for a number of minerals. The largest differences were observed for calcium, which was $30 \%$ higher in the prepared goat milk formula, and for iron, which was approximately $23 \%$ higher in the prepared cow milk formula. Levels of the remaining minerals were similar in the 2 formulas, with differences of less than $10 \%$. Because the cow milk infant formula was an adapted (whey-enhanced) formula and the goat milk formula was not, these differences may simply relate to different methods of processing as opposed to a species difference. The mineral levels of both formulas were within 50 to $120 \%$ of the average reported by Hamill et al. (1989), who analyzed 78 milk-based infant formulas.

When the formulas were prepared according to the manufacturer's instructions (13.5 g of DM to $90 \mathrm{~mL}$ of water for the goat milk formula, and $12.7 \mathrm{~g}$ of DM to 90 $\mathrm{mL}$ water for the cow milk formula) a different mineral pattern was observed. Calcium was present in greater amounts (32\% higher) in the prepared goat milk infant formula compared with that determined in the prepared cow milk formula. Phosphorus and manganese were approximately $14 \%$ higher in the liquid goat milk formula, whereas iron was $23 \%$ higher in the cow milk formula. The other minerals were present at similar levels in both formulas (equal to or less than a $3 \%$ difference). The calcium:phosphorus ratio was $16 \%$ higher in the liquid goat milk formula compared with the liquid cow milk formula.

With the exception of manganese, only minor differences were found between formulas for the absorption of individual minerals. For instance, the apparent absorption of calcium and phosphorus differed by less than $1.3 \%$, whereas no others were significantly different. Manganese absorption was $13 \%$ higher in piglets fed the goat milk formula compared with the cow milk infant formula. Total mineral digestibility for the minerals tested was also similar for both formulas and was very high (around 97\%). Murry et al. (1999) reported lower total mineral (ash) digestibility when measured in 28-d-old piglets fed either raw goat or cow milk than we found for the goat and cow milk formulas in this study. Moreover, Murry et al. found no significant difference between the total mineral digestibility of raw goat milk and raw cow milk. With such small differences between formulas for the digestibility of individual minerals, any differences in mineral retention are likely due to differences in the mineral contents of the 2 formulas. This is suggested by the similarity between the patterns of mineral retention (Table 5) and the absorbable mineral contents calculated for the 2 formulas (Table 3).

Perhaps the most important difference in absorbable mineral contents was that observed for calcium. Milk is an important source of dietary calcium and, as such, is discussed here in greater detail. The effect of cow and goat milk on the digestive and metabolic utilization of calcium was studied in rats (Lopez-Aliaga et al., 2000) and was shown to be greater with goat milk than with 

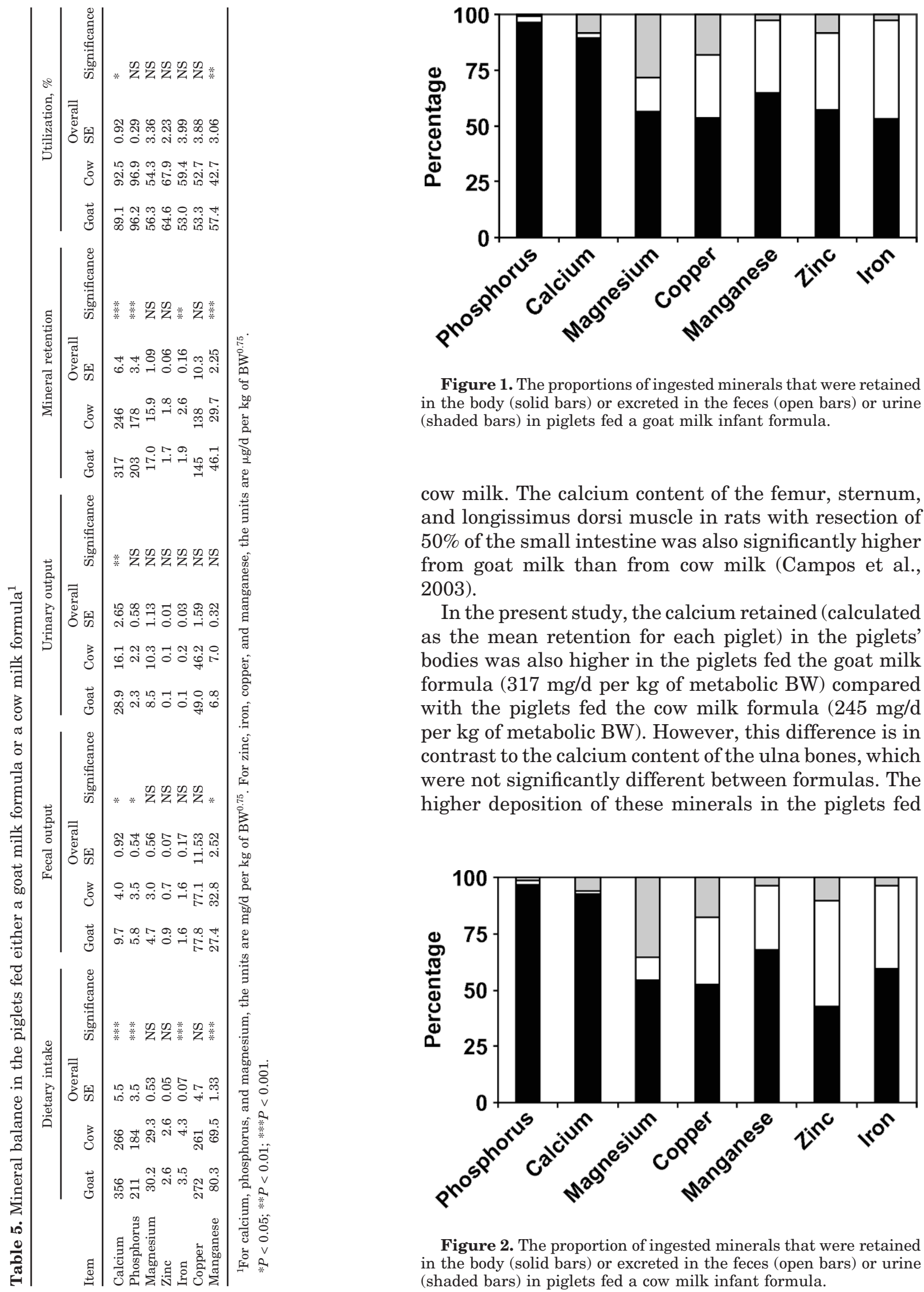

Figure 1. The proportions of ingested minerals that were retained in the body (solid bars) or excreted in the feces (open bars) or urine (shaded bars) in piglets fed a goat milk infant formula.

cow milk. The calcium content of the femur, sternum, and longissimus dorsi muscle in rats with resection of $50 \%$ of the small intestine was also significantly higher from goat milk than from cow milk (Campos et al., 2003).

In the present study, the calcium retained (calculated as the mean retention for each piglet) in the piglets' bodies was also higher in the piglets fed the goat milk formula (317 mg/d per $\mathrm{kg}$ of metabolic BW) compared with the piglets fed the cow milk formula $(245 \mathrm{mg} / \mathrm{d}$ per $\mathrm{kg}$ of metabolic BW). However, this difference is in contrast to the calcium content of the ulna bones, which were not significantly different between formulas. The higher deposition of these minerals in the piglets fed

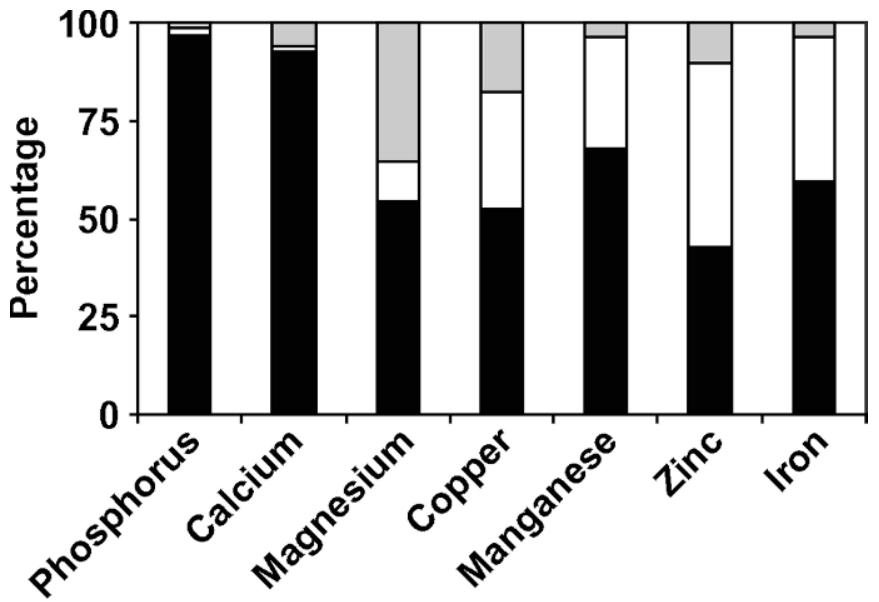

Figure 2. The proportion of ingested minerals that were retained in the body (solid bars) or excreted in the feces (open bars) or urine (shaded bars) in piglets fed a cow milk infant formula. 
the goat milk formula, compared with those fed the cow milk formula, may warrant further investigation, particularly to discover at which site the calcium is being deposited.

Pelegano et al. (1991) investigated the effect of dietary calcium:phosphorus ratio on the retention of calcium and phosphorus in parenterally fed premature infants and found significantly higher calcium retention in diets with a calcium:phosphorus ratio of $1.7: 1$ to $2.1: 1$, whereas phosphorus retention was greater in diets with a lower calcium:phosphorus ratio (1.3:1). This is consistent with the findings of this study, in which calcium retention was greater in the goat milk formula, which had a higher calcium:phosphorus ratio (1.68) compared with the cow milk formula (1.45).

In summary, both the goat and cow infant formulas had a very high digestibility for each of the minerals tested. The goat milk infant formula provided a pattern of mineral retention in the 3 -wk-old piglet very similar to that of the adapted cow milk infant formula. Any differences between the 2 appeared to be due to the different mineral contents of the 2 formulas. In terms of mineral digestibility and utilization, the goat milk formula would appear to be a suitable substitute for whey-enhanced cow milk infant formula in infants.

\section{REFERENCES}

Alferez, M. J. M., I. Lopez Aliaga, M. Barrionuevo, and M. S. Campos. 2003. Effect of dietary inclusion of goat milk on the bioavailability of zinc and selenium in rats. J. Dairy Res. 70:181-187.

Barrionuevo, M., M. J. M. Alferez, I. Lopez Aliaga, M. R. Sanz Sampelayo, and M. S. Campos. 2002. Beneficial effect of goat milk on nutritive utilization of iron and copper in malabsorption syndrome. J. Dairy Sci. 85:657-664.

Campos, M. S., I. Lopez Aliaga, M. J. M. Alferez, T. Nestares, and M. Barrionuevo. 2003. Effects of goats' or cows' milk on nutritive utilization of calcium and phosphorus in rats with intestinal resection. Br. J. Nutr. 90:61-67.

Darragh, A. J., and P. J. Moughan. 1995. The three-week-old piglet as a model for studying protein digestion in human infants. J. Pediatr. Gastroenterol. Nutr. 21:387-393.
D’Urso, G. 2000. Il latte di capra: Specificità e qualità nutritive. Latte 25:72-78.

Grant, C., B. Rotherham, S. Sharpe, R. Scragg, J. Thompson, J. Andrews, C. Wall, J. Murphy, and D. Lowry. 2005. Randomized, double-blind comparison of growth in infants receiving goat milk infant formula versus cow milk infant formula. J. Paediatr. Child Health 41:564-568.

Haenlein, G. F. W. 2004. Goat milk in human nutrition. Small Rumin. Res. 51:155-163.

Hamill, T. W., E. R. Young, R. R. Eitenmiller, C. D. Hogarty, and A. M. Soliman. 1989. Ca, P, Mg, Zn, Cu, Mn, Na, K and Cl contents of infant formulas manufactured in the United States. J. Food Comp. Anal. 2:132-139.

Jenness, R. 1980. Composition and characteristics of goat milk: Review 1968-1979. J. Dairy Sci. 63:1605-1630.

Lopez-Aliaga, I., M. J. M. Alferez, M. Barrionuevo, F. Lisbona, and M. S. Campos. 2000. Influence of goat and cow milk on the digestive and metabolic utilization of calcium and iron. J. Physiol. Biochem. 56:201-208.

Masson, P., P. Ohlsson, and I. Bjorkman. 1981. Combined enzymic Jaffe method for determination of creatinine in serum. Clin. Chem. 27:18-21.

Moughan, P. J., M. H. Birtles, P. D. Cranwell, W. C. Smith, and M. Pedraza. 1992. The piglet as a model animal for studying aspects of digestion and absorption in milk-fed human infants. World Rev. Nutr. Diet. 67:40-113.

Murry, A. C., S. Gelaya, J. M. Casey, T. L. Foutz, B. Kouakou, and D. Arora. 1999. Type of milk consumed can influence plasma concentration of fatty acids and minerals and body composition in infant and weaning pigs. J. Nutr. 129:132-138.

Park, Y. W., A. W. Mahoney, and D. G. Hendricks. 1986. Bioavailability of iron in goat milk compared with cow milk fed to anemic rats. J. Dairy Sci. 69:2608-2615.

Pelegano, J. F., J. C. Rowe, D. E. Carey, D. J. LaBarre, K. W. Edgren, A. M. Lazar, and E. Horak. 1991. Effect of calcium/phosphorus ratio on mineral retention in parenterally fed premature infants. J. Pediatr. Gastroenterol. Nutr. 12:351-355.

Rodrigeuz Rodrigeuz, E. M., M. Sanz Alaejos, and C. Diaz Romero. 2002. Mineral content of goats' milk. J. Food Qual. 25:343-358.

Roncada, P., A. Gaviraghi, S. Liberatori, B. Canas, L. Bini, and G. F. Greppi. 2002. Identification of caseins in goat milk. Proteomics 2:723-726.

Rutherfurd, S. M., A. J. Darragh, W. H. Hendriks, C. G. Prosser, and D. Lowry. 2006. True ileal amino acid digestibility of goat and cow milk infant formulas. J. Dairy Sci. 89:2408-2413.

SAS Institute. 1999. SAS User's Guide: Statistics. SAS Institute, Inc., Cary, NC.

Sawaya, W. N., J. K. Khalil, and A. F. Al-Shalhat. 1984. Mineral and vitamin content of goat's milk. J. Am. Diet. Assoc. 84:433-435. 